\title{
SISTEMA FINANCEIRO E CRESCIMENTO ECONÔMICO NO RIO GRANDE DO SUL
}

\author{
FINANCIAL SYSTEM AND ECONOMIC GROWTH IN RIO GRANDE DO SUL
}

\section{Ricardo Höher ${ }^{1}$}

ORCID: https://orcid.org/0000-0003-3790-0099

\section{Osmar Tomaz de Souza²}

ORCID: https://orcid.org/0000-0002-9854-8642

(Universidade Federal de Santa Maria - UFSM) ${ }^{1}$

(Pontifícia Universidade Católica do Rio Grande do Sul - PUCRS)²

\section{RESUMO}

O presente trabalho buscou testar a hipótese sobre a existência de uma correlação positiva entre desenvolvimento financeiro e crescimento econômico no Rio Grande do Sul e suas mesorregiões, por meio das técnicas de Regressão Quantílica, tendo como variável dependente o Produto Interno Bruto - PIB per capita e variáveis independentes o valor de crédito rural per capita, operações de crédito per capita e a existência de Postos de Atendimento - PAs de cooperativas de crédito nos municípios. Os resultados da aplicação empírica comprovaram a existência de relação positiva entre desenvolvimento do sistema financeiro e o crescimento econômico do Rio Grande do Sul e suas mesorregiões, destacando a importância da pesquisa para os estudos dedicados ao desenvolvimento econômico regional.

Palavras-chave: PIB. Crédito Rural. Cooperativa de crédito.Economia regional.

\section{ABSTRACT}

The present paper sought to test the hypothesis about the existence of a positive correlation between financial development and economic growth in Rio Grande do Sul and its mesoregions, through Quantum Regression techniques, having as a dependent variable the Gross Domestic Product - GDP per capita and independent variables, the value of rural credit per capita, credit operations per capita, and the existence of Service Stations - SSs of credit cooperatives in the municipalities. The results of the empirical application have confirmed the existence of a positive relation between the development of the financial system and the economic growth of Rio Grande do Sul and its mesoregions, highlighting the importance of research for studies dedicated to regional economic development.

Keywords: GDP. Rural credit. Credit cooperative. Regional economy. 


\section{INTRODUÇÃO}

A literatura econômica apresenta, de forma quase que consensual, o desenvolvimento financeiro como aspecto positivo para o fluxo da atividade econômica, tendo como um dos principais mecanismos para tal, a oferta de crédito. Para Reichstul e Lima (2006), as operações de crédito devem ser realizadas em condições adequadas de prazo, custos e quantidades, assim como, possibilidade de oportunizar investimentos promissores.

A concessão de crédito é supervisionada pelo Banco Central do Brasil - BCB e tem como operadores os Bancos, as Caixas Econômicas, as Cooperativas de Créditos, as instituições de pagamentos (não compõem o Sistema Financeiro Nacional - SFN) e demais instituições não bancárias.

Dentre tais instituições, o sistema financeiro cooperativo se destaca por algumas particularidades que os diferencia dos demais. Nesse tipo de instituição um mesmo indivíduo é o proprietário e o cliente, portanto o empreendimento prospera em razão da intensidade da cooperação e do trabalho do associado. Outro aspecto é a capacidade de impulsionar o crescimento local, pois assegura o investimento dos recursos na comunidade de origem, o que, para Meinen (2016, p.18), “...cria um círculo virtuoso que leva à geração de novos empregos, ao aumento do consumo e, por via da elevação da receita tributária, amplia a capacidade de investimento em saúde e na educação das populações residentes". Ainda para o autor, a aptidão da população associada ao potencial da região e envolvida nas ações cooperativistas, pode proporcionar ganhos socioeconômicos para a população em geral, não só ao associado.
Assim comoas cooperativas de créditos, os demais operadores de sistema financeiro, em especial bancos e caixas econômicas, também contribuem para o desenvolvimento financeiro, por intermédio das operações financeiras, concedendo crédito para a atividade produtiva. Outros importantes agentes são os bancos de desenvolvimento, que têm como objetivo oportunizar recursos para o financiamento, a médio e longo prazo, para programas e projetos que visem promover o desenvolvimento econômico e social de determinadas regiões ou atividades econômicas, como é o caso do crédito rural $(B C B$, 2018).

O crédito rural tem importante participação no crescimento econômico, pois é a principal fonte de financiamento da atividade agropecuária, que depende deste tipo de recurso, pois sua produção é sazonal, necessita de longos prazos para maturação do processo produtivo e também pelo descompasso temporal entre despesas e receitas (BUAINAIN et al., 2014).

A proposta deste trabalho trata dos argumentos teóricos que discutem a relevância do sistema financeiro como um dos fatores promotores do crescimento econômico, no qual pretende testar a hipótese sobre a existência de uma correlação positiva entre sistema financeiro (crédito rural, operações de crédito e cooperativismo financeiro) e crescimento econômico no Rio Grande do Sul e suas mesorregiões, por meio das técnicas de Regressão Quantílica.

Diferentemente de outros trabalhos similares, que utilizaram outras variáveis e técnicas econométricas, bem como a aplicação em outras regiões e países, este estudo se dedicou a apresentar os impactos que o crédito rural, as 
operações de crédito e a presença de cooperativas financeiras nos municípios têm no crescimento econômico do Rio Grande do Sul, bem como para cada mesorregião do Estado, assim, apontando resultados inéditos neste sentido. Para tal, teve a pretensão de responder o seguinte problema:

Quais os impactos econômicos das variáveis crédito rural, operações de crédito e presença de cooperativa financeira (dummy) no crescimento econômico (PIB) do Rio Grande do Sul e nas suas mesorregiões?

Para isto, o presente trabalho foi estruturado, além dessa seção introdutória, em mais cinco seções, em que a seguinte aborda o cooperativismo de crédito no Brasil e posteriormente as teorias sobre a relação entre desenvolvimento financeiro e o crescimento econômico. Na sequência foram apresentados os aspectos metodológicos e posteriormente, os resultados obtidos e, por fim, o trabalho foi encerrado com as conclusões sobre o estudo realizado.

\section{COOPERATIVISMO DE CRÉDITO NO BRASIL}

Em 28 de dezembro de 1902 foi constituída a primeira cooperativa de crédito no Brasil, com sede na cidade de Nova Petrópolis, Rio Grande do Sul, atualmente denominada Cooperativa de Crédito de Livre Admissão de Associados Pioneira da Serra Gaúcha - SICREDI Pioneira/RS. A partir de 1902 até 1964, só no Rio Grande do Sul, foram constituídas mais 66 cooperativas de crédito do tipo Raiffeisen ${ }^{1}$ e em março de 1906 foi constituída a primeira cooperativa de crédito do tipo Luzzatti² no Brasil, também no estado gaúcho, atualmente, conhecida como Cooperativa de Crédito de Lajeado (PINHEIRO, 2008).

Com a abertura oficial ao crédito cooperativo no Brasil, promovida em 2003, por meio das resoluções Resolução BACEN n. ${ }^{\circ} 3.106$ e Resolução BACEN n. ${ }^{\circ} 3.140$ houve, desde então, uma expansão deste segmento. Tais resoluções permitiram a inclusão social de pequenos empresários, microempresários e micro empreendedores, via cooperativas de crédito, bem como estendeu para os médios e grandes empresários, o que oportunizou a constituição de inúmeras cooperativas de crédito desde então (PINHO; PALHARES, 2004).

As cooperativas de crédito têm sido importantes agentes no crescimento econômico de regiões esquecidas pelos bancos tradicionais, no qual proporcionam inclusão financeira para a população excluída, por falta de acesso ou de menor poder aquisitivo. A presença dessas instituições pode promover a geração de emprego e renda, assim como auxiliar na redução da pobreza (CHAVES, 2011).

A distribuição espacial das cooperativas de crédito não tem se apresentado de maneira uniforme. De acordo com o relatório do Banco Central do Brasil, Panorama do Sistema Nacional de Crédito Cooperativo, a região Sul apresenta a participação mais expressiva com aproximadamente metade dos principais agregados do cooperativismo de crédito no país, com 45,91\% das unidades de atendimento, $49,61 \%$ dos Ativos, $48,61 \%$ das carteiras de crédito e 52,53\% depósitos.

\footnotetext{
${ }^{1}$ Cooperativa de crédito rural - Constituída por Friedrich Wilhelm Raiffeisen.

2 Livre associação - implantada por Luigi Luzzatti.
} 
As cooperativas estabelecidas na região sudeste compreendem em torno de $30 \%$ dos principais agregados das cooperativas de crédito, com $38,83 \%$ das unidades de atendimento, 32,14\% dos Ativos, 28,60\% das carteiras de crédito e 28,63\% dos depósitos.

A região centro-oeste aparece como a terceira mais representativa com 9,02\% das unidades de atendimento, $14,18 \%$ dos Ativos, 15,82\% das carteiras de crédito, $12,25 \%$ depósitos. Na sequência aparece o Nordeste com 5,56\% das unidades de atendimento, 3,93\% de Ativos, 3,86\% das carteiras de crédito e 4,38\% dos depósitos Por fim, a região norte com a seguinte participação nos agregados: 4,10\% das unidades de atendimento, $2,43 \%$ dos Ativos, 3,10\% das carteiras de crédito e 2,22\% depósitos.

No sentido de facilitar a expansão do cooperativismo financeiro para todo território nacional, o Banco Central do Brasil estabelece, por meio da Resolução BACEN n. ${ }^{\circ} 4.434$, que relata sobre a constituição, a liberação para funcionamento, o funcionamento, as alterações estatutárias e o cancelamento de autorização para funcionamento das cooperativas de crédito e dá outras providências, o que permitirá que cooperativas de crédito de uma determinada região possam abrir sede em outros territórios.

A legislação aplicada ao cooperativismo financeiro tem caminhado no sentido de contribuir para a expansão desse segmento, em especial para as regiões mais periféricas e menos favorecidas pelos bancos comerciais, como as pequenas cidades, assim possibilitando acesso ao crédito pela população de baixa renda e ampliando o microcrédito. Além da expansão na atuação territorial, os avanços dos aspectos legais têm oportunizado, para esses agentes financeiros, aplicar taxas de juro mais baixas, em comparação a alguns bancos tradicionais, oferecer atendimento personalizado ao associado (cliente) e concessão do crédito mais ágil, com menor burocrática, o que tem possibilitado desenvolvimento socioeconômico para tais localidades(Paiva; Santos, 2017).

\section{SISTEMA FINANCEIRO E CRESCIMENTO ECONÔMICO}

Schumpeter (1911) foi quem realizou as primeiras considerações sobre a importante relação entre o sistema financeiro e o crescimento econômico, em que relacionou financiamento ao processo de inovação como importante fator para o desenvolvimento. A partir daí, outros trabalhos apontaram evidências empíricas, como os estudos de Goldsmith (1969), Shaw (1973), Levine (1997) e Khan (1999), que constataram uma relação positiva entre sistema financeiro e crescimento econômico. Ainda nessa lógica Ivo et al (2016) afirmam que o crédito contribui para o desenvolvimento econômico, pois gera capacidade de inovações no qual incentiva o ciclo econômico, assim permitindo que o mercado amplie forças produtivas necessárias para a produção de bens e serviços.

Segundo Levine (1997), o sistema financeiro impacta no crescimento econômico por meio da acumulação de capital e pelos efeitos, no sentido de gerar inovação tecnológica, por meio de investimentos. A taxa de poupança pode interferir na decisão de formação de capital ou a realocação dos recursos em tecnologias produtoras de capital, assim aumentando a produtividade 
do investimento.Para tal, foi concebida a ideia de que a disponibilidade de recursos financeiros parte da captação de valores destinados à poupança e que, quando alocados de maneira na atividade empresarial, podem promover o crescimento econômico, sendo papel do sistema financeiro operacionalizar e intermediar as transações entre poupadores e tomadores.
As falhas no canal de transmissão das informações entre poupadores e tomadores de recursos, são condições basilares para a existência do sistema financeiro, que surge como agente redutor dessa imperfeição de mercado e facilitador para transmissão de recursos para setor produtivo, conforme representa a Figura 1 (SILVA; PORTO JUNIOR, 2006).

Figura 1 - Funcionamento do Sistema Financeiro.
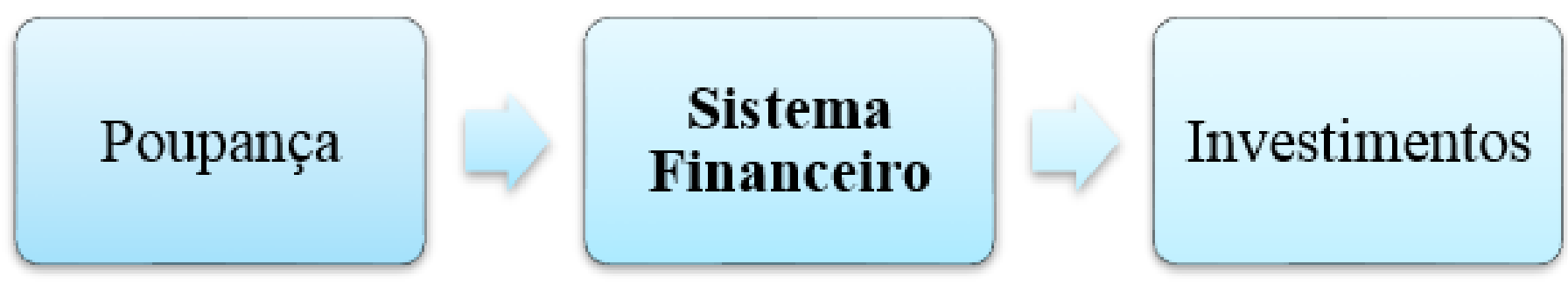

Fonte: Elaborado pelo autor a partir de Bebczuk, 2003.

O sistema financeiro reduz a assimetria de informações entre poupadores e investidores, o que promove a alocação de recursos de forma mais ajustada às necessidades de cada agente. Silva e Porto Junior (2006), listam algumas funções do sistema financeiro:

Mobilização de recursos - O sistema financeiro tem acesso à poupança de vários indivíduos.

Alocação dos recursos no espaço e no tempo - O sistema financeiro possibilita satisfazer os poupadores que buscam transações de curto prazo, garantindo a liquidez e os tomadores que investem os recursos em projetos de longo prazo.

Administração do risco - Os agentes financeiros apresentam-se mais preparados para avaliar os projetos que irão realizar os empréstimos, assim como uma maior diversificação de firmas e setores.

Seleção e monitoramento de empresas - Os agentes financeiros possuem conhecimento técnico para selecionar e monitorar os melhores projetos de investimentos.

Produção e divulgação de informação - A assimetria de informação pode gerar problema de seleção adversa ${ }^{3}$ e de risco moral ${ }^{4}$, tais problemas podem ser minimizados pelos agentes financeiros, que além de reduzir riscos para o sistema financeiro sinaliza a situação econômica do tomador para o mercado.

Keynes (1964), dentro da lógica do sistema capitalista, reconhece a importância do setor financeiro, pois permite satisfazer o interesse dos tomadores de recursos, em investimentos com

\footnotetext{
3 Refere-se às escolhas equivocadas de determinados bens ou serviços ofertados no mercado (VARIAN, 1990).

${ }^{4}$ Refere-se à mudança de comportamento de um agente de acordo com as diferentes situações nas quais podem ocorrer uma transação econômica (VARIAN, 1990).
} 
retornos de longo prazo e, por outro lado, garantir a liquidez para os poupadores. Eliminando, assim, o problema gerado pela necessidade de renegociação de contratos de financiamento, o que poderia gerar uma alteração das taxas de juros em virtude de algum desequilíbrio econômico. Portanto, o setor financeiro viabiliza o processo de alongamento de empréstimos, com taxas de juros similares aos de contratos de curto prazo. Então, conforme o nível de desenvolvimento do setor financeiro ou dos aspectos regulatórios existentes pode-se obter impactos positivos para o crescimento econômico.

Conforme Myrdal (1968) e Kaldor (1970) os agentes financeiros locais, de maneira geral, não possuem autonomia monetária quanto ao destino dos créditos ofertados, o que associa o impacto do sistema financeiro sobre o desenvolvimento do país, para esse sim refletir no crescimento regional. Outro posicionamento, dentro dessa dinâmica, refere-se às cooperativas de crédito, que ofertam os créditos na comunidade em que estão instaladas. Em pesquisas pós-Keynesiana, argumenta-se que bancos com abrangência local promovem o desenvolvimento regional, pois disponibilizam crédito para a comunidade onde estão inseridos. Para os teóricos pós-keynesianos, o sistema financeiro é a base para promover o crescimento econômico, pois podem adiantar recursos para o processo de investimento de longo prazo e de garantir a liquidez necessária. Operações de longo prazo envolvem expectativas mais incertas, que são reduzidas pela atuação dos agentes financeiros.

Para alguns autores, como Perroux (1967) e Kaldor (1970), o estudo sobre desenvolvimento das regiões e locais não aborda diretamente a participação do sistema financeiro dentro do ambiente da economia regional, mesmo o crédito sendo um fator relevante para potencializar o crescimento econômico local. Entende-se que o crédito segue o desenvolvimento regional e de maneira afirmativa, Fialho et al (2016) afirmam que são preliminares e raras pesquisas que correlacionam sistema financeiro desenvolvido com o crescimento econômico no Brasil, em especial quando relacionam os efeitos nos indicadores de pobreza e renda do país. Como contraponto dessa afirmação, Guiso, Sapienza e Zingales (2002), abordam uma visão em que o sistema financeiro, ao ofertar crédito, fortalece o desenvolvimento financeiro local, o que gera impacto positivo sobre o crescimento econômico da região, assim destaca que o desenvolvimento financeiro local é fator determinante para o crescimento econômico local. Castro (2002), concluiu em seus estudos, em algumas regiões do Brasil, que quanto mais dinâmica for a economia regional e mais elevada sua produtividade, maior será o interesse em reter depósitos e menor sua preferência por liquidez. Sicsú e Crocco (2003), dentro dessa dinâmica explicaram a distribuição das agências bancárias em regiões com maior potencial produtivo.

No caso da economia brasileira, que se caracteriza pela relevante participação do setor agropecuário, com um PIB de R \$263,6 bilhões em 2015, segundo o Instituto Brasileiro de Geografia e Estatística - IBGE, sendo um em plena expansão com a incorporação de novas áreas produtivas e tecnologias. A produção da atividade agropecuária é sazonal, dependente dos fatores climáticos, sendo o crédito fundamental. Portanto, para acompanhar esse processo de crescimento, se faz necessário capital para satisfazer tais demandas. Nesse 
sentido, a política de concessão de crédito rural abrange recursos direcionados para custeio, com o objetivo de financiar a produção, investimento, para aquisição de bens de capital, e comercialização, para facilitar as vendas (PINTOR et al., 2016).
Os aspectos teóricos, mencionados nessa seção, corroboram com estudos empíricos que relacionaram o sistema financeiro com o crescimento econômico, conforme demonstra Quadro 1.

Quadro 1 - Estudos sobre o Sistema Financeiro e crescimento econômico

\begin{tabular}{|c|c|c|}
\hline PESQUISADOR & TÍTULO & ANO \\
\hline Goldsmith & Financial struture and development. & 1969 \\
\hline Khan & Financial development and economic growth. & 1999 \\
\hline Reichstul e Lima & $\begin{array}{l}\text { Casualidade entre crédito bancário e nível de } \\
\text { atividade econômica na região Metropolitana de São } \\
\text { Paulo. }\end{array}$ & 2006 \\
\hline Silva e Porto Jr & $\begin{array}{l}\text { Sistema financeiro e crescimento econômico: } \\
\text { uma aplicação de regressão quantílica. }\end{array}$ & 2006 \\
\hline $\begin{array}{l}\text { Ivo, Cruz, Chinelato e } \\
\text { Ziviani }\end{array}$ & \begin{tabular}{|} 
A expansão do crédito no Brasil: uma \\
ferramenta para o desenvolvimento socioeconômico
\end{tabular} & 2016 \\
\hline $\begin{array}{l}\text { Fialho, Jayme Jr e } \\
\text { Hermeto }\end{array}$ & $\begin{array}{l}\text { Desenvolvimento do sistema financeiro e } \\
\text { pobreza no Brasil: uma análise multivariada. }\end{array}$ & 2016 \\
\hline $\begin{array}{l}\text { Pintor, Pintor, Oliveira e } \\
\text { Wesz Junior }\end{array}$ & $\begin{array}{l}\text { Crédito rural e crescimento econômico na } \\
\text { mesorregião Oeste do Paraná. }\end{array}$ & 2016 \\
\hline
\end{tabular}

Fonte: Elaborado pelo autor.

Segue, na próxima seção, a apresentação da metodologia que foi utilizada na execução da pesquisa empírica, em conformidade com os aspectos teóricos abordados.

\section{METODOLOGIA}

Nas seções anteriores abordaram-se os insights teóricos sobre a participação do sistema financeiro para o crescimento econômico. No propósito de atingir os objetivos deste trabalho, e para a execução de pesquisa empírica, foi realizada uma Regressão Quantílica - RQ.

Por meio da RQ, buscou-se avaliar os efeitos da concessão de crédito rural, do volume das operações de crédito e a existência de Postos de Atendimento
- PAs das cooperativas de crédito no PIB (medida de crescimento econômico) do Rio Grande do Sul, bem como nas mesorregiões do Estado. Para tal, foi elaborado um modelo em que se considerou que a variação da variável dependente (PIB) é explicada em função das variáveis independentes (crédito rural, operações de crédito e PAs de cooperativas de crédito). Conforme o BCB, 92\% dos municípios gaúchos possuem cooperativas de crédito, o maior percentual entre os estados da federação, o que justifica a escolha dessa unidade federativa.

Os dados aplicados para satisfazer o modelo foram os valores do PIB per capita dos 497 municípios gaúchos, disponibilizados pelo Instituto Brasileiro de Economia e Estatística - IBGE, os valores do crédito rural per capita concedidos para cada cidade do Rio Grande do Sul e a distribuição 
dos PAs das cooperativas de crédito nos municípios gaúchos, ambos disponíveis pelo Banco Central do Brasil - BCB. Da mesma forma, as informações referentes aos valores das operações de créditos per capita realizadas pelos bancos comerciais nessas cidades foram disponibilizados pela Fundação de Economia e Estatística - FEE. Todos os dados e informações são de 2015 (onde as diferentes informações utilizadas já estão consolidas nos sistemas de dados das instituições - IBGE, BCB e FEE).

Para Wooldridge (2013), a análise de regressão múltipla permite utilizar mais de um fator, de forma simultânea, que podem afetar a variável dependente, sendo importante ferramenta para testar teorias econômicas com dados não experimentais.

Diante do suporte teórico apresentado, neste trabalho, buscou-se elaborar um modelo que representasse os efeitos do crédito e dos agentes financeiros no crescimento econômico. Para tal propósito foi elaborado o seguinte modelo econométrico:

$P I B=\beta_{0}+\beta_{1} C R E D R U R A L+\beta_{2}$ OPCREDITO + $\delta_{3}$ PCOOPCRED $+\varepsilon$

Onde,

PIB representa o Produto Interno Bruto per capita dos municípios do Rio Grande do Sul;

CREDRURAL é o valor de crédito rural per capita concedido por município;

OPCREDITO são os valores referentes aos financiamentos e empréstimos per capita realizados por meio dos bancos comerciais nas cidades gaúchas;
PCOOPCRED considera a existência de PAs de cooperativas de crédito estabelecidas nas cidades do Rio Grande do Sul. Representa uma variável dummy em que 1 significa que possui PA e 0 que não possui.

Ainda cabe considerar que $\beta_{0}$ é o intercepto, $\beta_{1}$ avalia as mudanças no PIB per capita em relação ao CREDRURAL per capita, mantendo os outros fatores fixos, $\beta_{2}$ representa as alterações no PIB per capita provocadas pela variável OPCREDITO per capita, mantendo os demais fatores fixos, e $\delta_{3}{ }^{5}$ provoca as alterações no PIB per capita considerando a presença ou não de PA de cooperativas de crédito no município. Tais coeficientes (parâmetros) permitem medir o efeito, ceteris paribus, das variáveis independentes na variável dependente.

O modelo proposto é aplicado em oito regiões, sendo a primeira no Rio Grande do Sul, englobando todos os municípios e, posteriormente, nas sete mesorregiões do Estado: Centro Ocidental, Centro Oriental, Metropolitana, Nordeste, Noroeste, Sudeste e Sudoeste. Após a aplicação da regressão nas regiões definidas, foram realizadas inferências e análises, iniciando pelo teste t dos parâmetros. Posteriormente foi realizada análise de pressuposto como intuito de identificar problema de colinearidade. Assim, como o teste de normalidade dos resíduos. Considerando o p-valor do teste $t$, onde a hipótese nula é rejeitada ou não, ao nível de significância. Para este estudo tal nível foi arbitrado em no máximo 10\% para rejeitar a hipótese nula. Conforme Wooldridge (2013, p. 1260):

${ }^{5}$ Coeficiente da variável dummy. 
O p-valor resume, com precisão, a força e a fraqueza da evidência empírica contra a hipótese nula. Talvez a interpretação mais útil seja a seguinte: o p-valor é a probabilidade de observar uma estatística t tão extrema quanto aceitarmos se a hipótese fosse verdadeira. Isso significa que p-valores pequenos são evidências contra a hipótese nula; p-valores grandes fornecem pouca evidência contra $\mathrm{H}_{0}$.

A regressão por Mínimos Quadrados Ordinários - MQO apresenta uma reta de regressão para o caso da média. Portanto, na perspectiva de obter um mapeamento mais preciso da interferência das variáveis explicativas sobre o crescimento econômico, buscou-se apurar como cada quantil responde, considerando a mediana. Dessa forma, foi preferida a utilização da técnica de Regressão Quantílica - RQ.

Considerando que as variáveis selecionadas para o caso dos municípios gaúchos apresentam forte desigualdade de valores, o que justifica o uso da regressão quantílica para tornar o modelo mais robusto à resposta de cada quantil e outliers (MARIONI et al, 2016). Portanto, para o estudo proposto, a regressão quantílica é mais adequada que a regressão por Mínimos Quadrados Ordinários.

Regressão quantílica pode ser vista como uma extensão natural dos quantis amostrais para o caso de um modelo linear $y=\beta_{0}+\beta_{1} X+\varepsilon$, que assume a seguinte forma:

$$
\min ^{-1}\left\{\Sigma \theta|y-\beta x|+\Sigma(1-\theta|y-\beta x|\}=\min ^{-1} \sum \rho_{\theta}(y-\beta x)\right.
$$

Em que $\rho$ que é a função "check" definida por:

$$
\rho_{\theta}(u)=\left\{\begin{aligned}
\theta u, & u \geq 0 \\
(\theta-1) u, & u<0
\end{aligned}\right.
$$

em que a função $\rho_{\theta}$ multiplica os resíduos por $\theta$, se eles forem não-negativos e por $(\theta-1)$, caso contrário, para que, dessa forma, sejam tratados assimetricamente.

\section{RESULTADOS E DISCUSSÃO}

De acordo com o modelo estimado, os resultados obtidos na Tabela 1 Modelo Rio Grande do Sul, demonstram que para cada real de crédito rural concedido o PIB per capita aumentou R \$1,47, já a variável operações de crédito não foi significativa para esse modelo. Os 426 municípios gaúchos que possuem postos de atendimento de cooperativa de crédito apresentaram, em média, um valor de $\mathrm{R} \$$ 3.303,96 no PIB per capita maior que os municípios que não possuem esses serviços bancários. Tal informação pode indicar a importância das cooperativas para o acesso ao crédito, bem como ferramenta de intermediação na concessão do crédito rural. Essa mesma análise foi aplicada nas sete mesorregiões, onde estão distribuídos os 497 municípios gaúchos de acordo com o IBGE. 
Tabela 1 - Modelo RQ Rio Grande do Sul

Estimativas dos quantis, usando as observações 1- 497

Variável dependente: PIBper. tau ${ }^{6}=0,5$

\begin{tabular}{|c|c|c|c|c|}
\hline & coeficiente & erro padrão & razão-t & $p$-valor \\
\hline Const & $16.897,80$ & 1346,88 & 12,55 & $0,0000 * * * 7$ \\
\hline CREDRURALper & 1,46836 & 0,0953555 & 15,40 & 0,0000 \\
\hline OPCREDITOper & $-0,010917$ & 0,00991906 & $-1,101$ & 0,2716 \\
\hline PCOOPCRED & $3.303,96$ & 1405,81 & 2,350 & 0,0192 ** \\
\hline \multicolumn{2}{|c|}{ Mediana var dependente } & D.P. var. dependente & 19333,04 & \\
\hline \multicolumn{2}{|c|}{ Soma resíd. absolutos } & Soma resíd. quadrados & $1,66 e+11$ & \\
\hline Log da verossimilhança & $-5357,794$ & Critério de Akaike & 10723,59 & \\
\hline \multicolumn{2}{|c|}{ Critério de Schwarz } & Critério Hannan-Quinn & 10730,20 & \\
\hline
\end{tabular}

Teste da normalidade dos resíduos -

Hipótese nula: o erro tem distribuição Normal

Estatística de teste: Qui-quadrado(2) $=4190,91$

com p-valor $=0,000$

Fatores de Inflação da Variância (FIV)

Valor mínimo possível = 1,0

Valores $>10,0$ podem indicar um problema de colinearidade

CREDRURALper $\quad 1,007$

OPCREDITOper $\quad 1,002$

PCOOPCRED $\quad 1,008$ independente

$V I F(j)=1 /(1-R(j) \wedge 2)$, onde $R(j)$ é o coeficiente de correlação múltipla entre a variável j e a outra variável Fonte: Elaborado pelo autor.

A partir dos resultados obtidos no modelo Rio Grande do Sul, a Figura 2 demonstrou graficamente o PIB per capita para os municípios gaúchos, bem como os valores previstos pelo modelo.

\footnotetext{
${ }^{6}$ Quantis desejados.

7 Grau de confiança - *** significante ao nível de 1\%; ** significante ao nível de 5\%; e * significante ao nível de 10\%.
} 
Figura 2 -Previsão do PIB per capita Rio Grande do Sul.

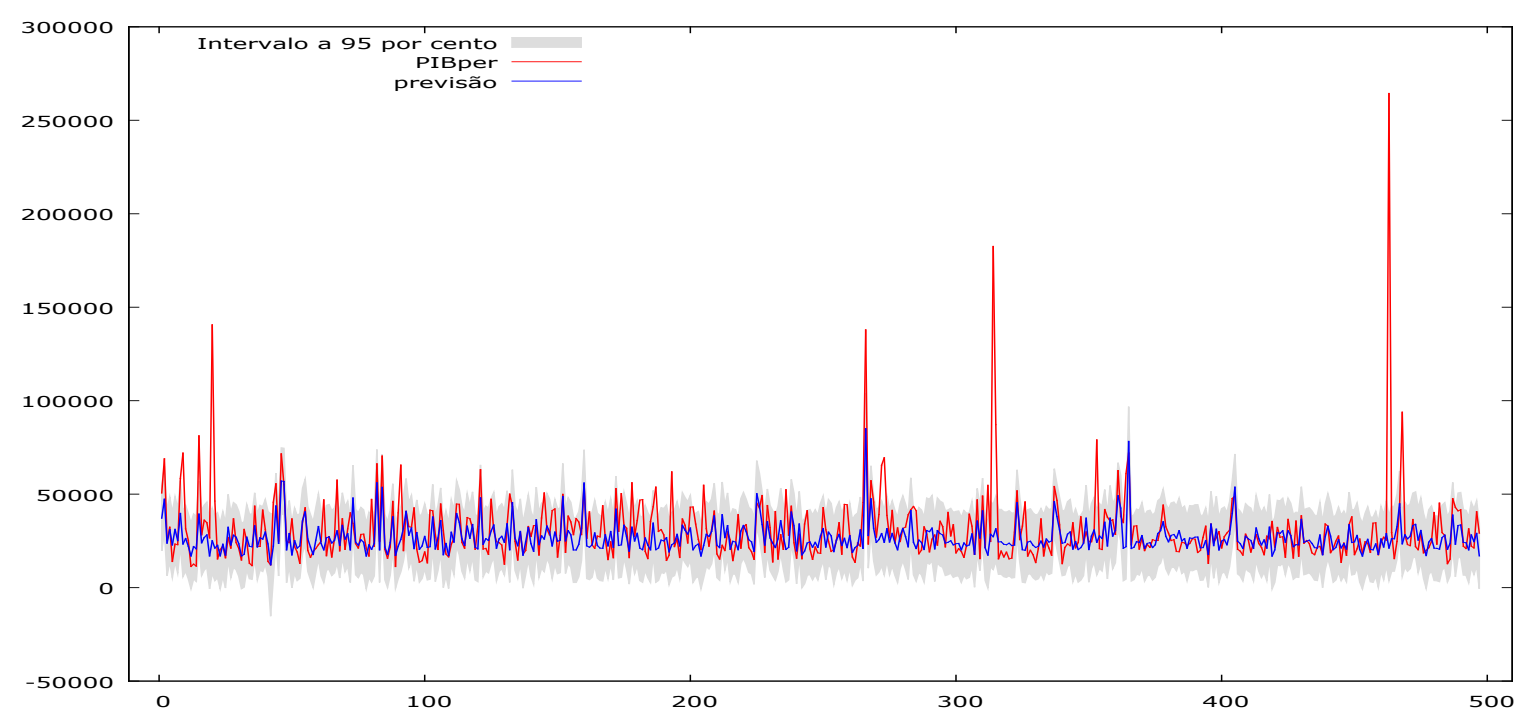

Fonte: Elaborado pelo autor.

Xxxx Intervalo de $95 \%$ de confiança.

------- PIB per capita para os municípios do Rio Grande do Sul.

------- Previsão do PIB per capita de acordo com o modelo proposto.

A mesorregião Centro Ocidental do Estado tem Maria com uma população de aproximadamente um PIB de 14.594.096.657,00 e agrupa 31 cidades, conforme a Figura 3, com destaque para Santa 280 mil habitantes e um PIB de $\mathrm{R} \$ 6.357 .789,01$ (mil) em 2015.

Figura 3 -Previsão do PIB per capita na mesorregião Centro-Ocidental.
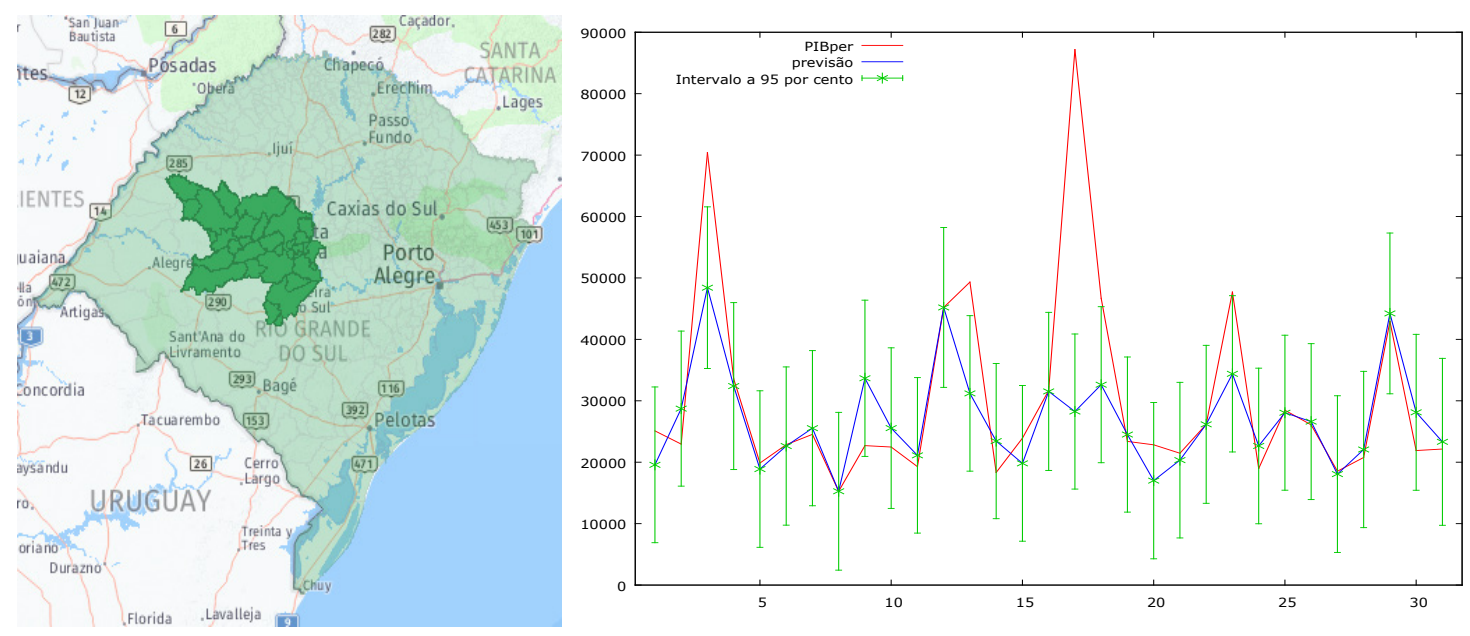

Fonte: Elaborado pelo autor

Intervalo de 95\% de confiança.

PIB per capita para os municípios do Rio Grande do Sul.

Previsão do PIB per capita de acordo com o modelo proposto. 
Os resultados da Regressão Quantílica referentes

na Tabela 2.

à mesorregião Centro Ocidental estão apresentados

Tabela 2 - Modelo RQ Centro Ocidental

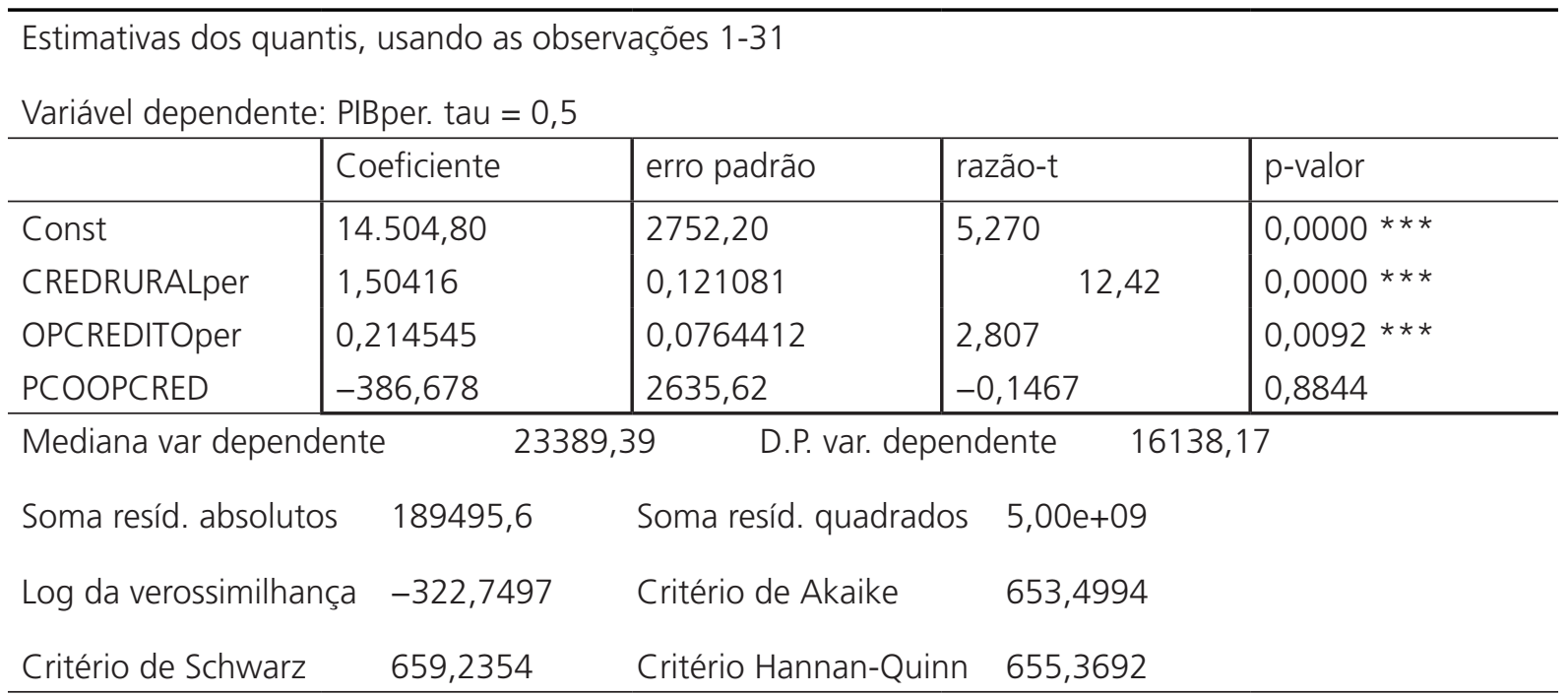

Teste da normalidade dos resíduos -

Hipótese nula: o erro tem distribuição Normal

Estatística de teste: Qui-quadrado(2) = 59,8102

com p-valor $=1,02889 \mathrm{e}-013$

Fatores de Inflação da Variância (FIV)

Valor mínimo possível = 1,0

Valores $>10,0$ podem indicar um problema de colinearidade

CREDRURALper $\quad 1,076$

OPCREDITOper $\quad 1,101$

PCOOPCRED $\quad 1,026$

$V I F(j)=1 /(1-R(j) \wedge 2)$, onde $R(j)$ é o coeficiente de correlação múltipla entre a variável j e a outra variável independente

Fonte: Elaborado pelo autor.

Na Aplicação, o modelo RQ estimado para os municípios da mesorregião Centro Ocidental do Rio Grande do Sul, conforme Tabela 2, verificouse que para cada real correspondente ao crédito rural concedido o PIB per capita aumentou $\mathrm{R} \$$ 1,50 e para cada real de operações de crédito o acréscimo foi de $R \$ 0,21$. A existência de cooperativa de crédito nos municípios não apresentou resultado significativo estatisticamente.

A mesorregião Centro Oriental (Figura 4) abrange 54 cidades gaúchas, com um PIB de R\$ 28.013.405.211,00 e uma população em torno 
de 830.000 habitantes. Com destaque para participação de $28 \%$ do PIB e $15 \%$ da população o município de Santa Cruz do Sul, com uma da mesorregião.

Figura 4 - Previsão do PIB per capita na mesorregião Centro-Oriental.
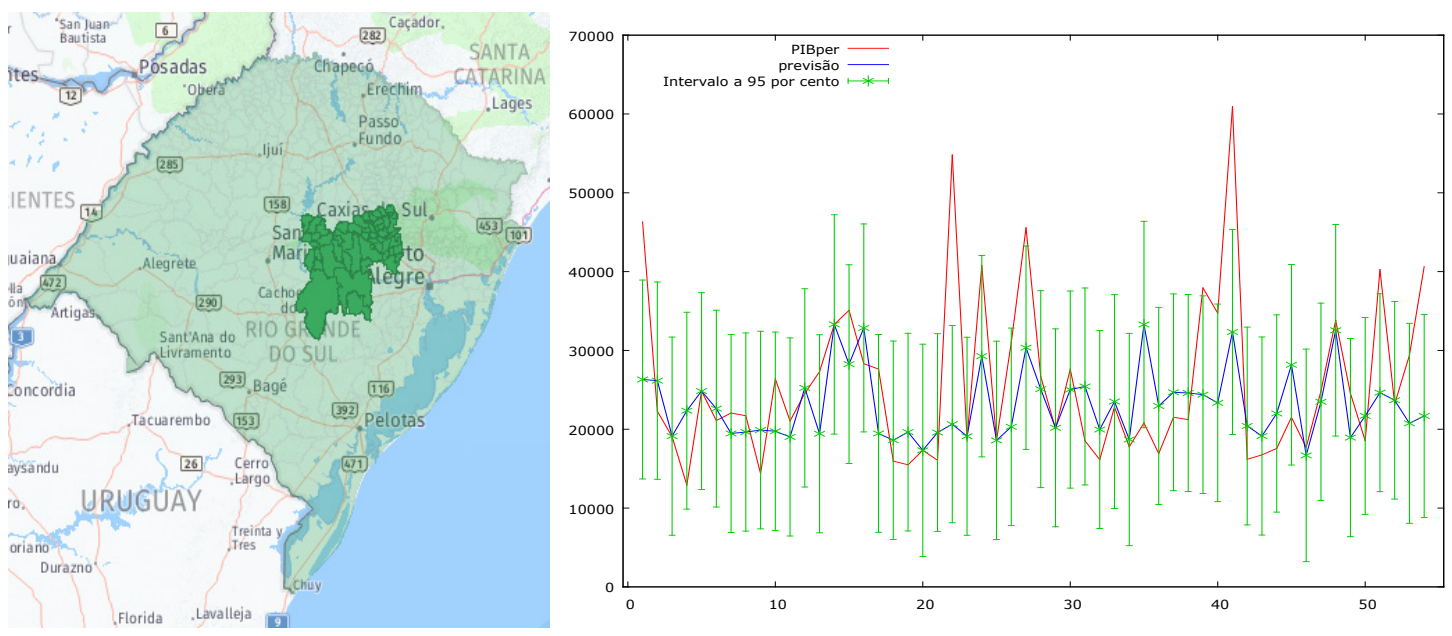

Fonte: Elaborado pelo autor.

Intervalo de $95 \%$ de confiança.

PIB per capita para os municípios do Rio Grande do Sul.

Previsão do PIB per capita de acordo com o modelo proposto.

A Tabela 3 apresenta os resultados da Regressão Grande do Sul.

Quantílica da mesorregião Centro Oriental do Rio

Tabela 3 - Modelo RQ Centro Oriental

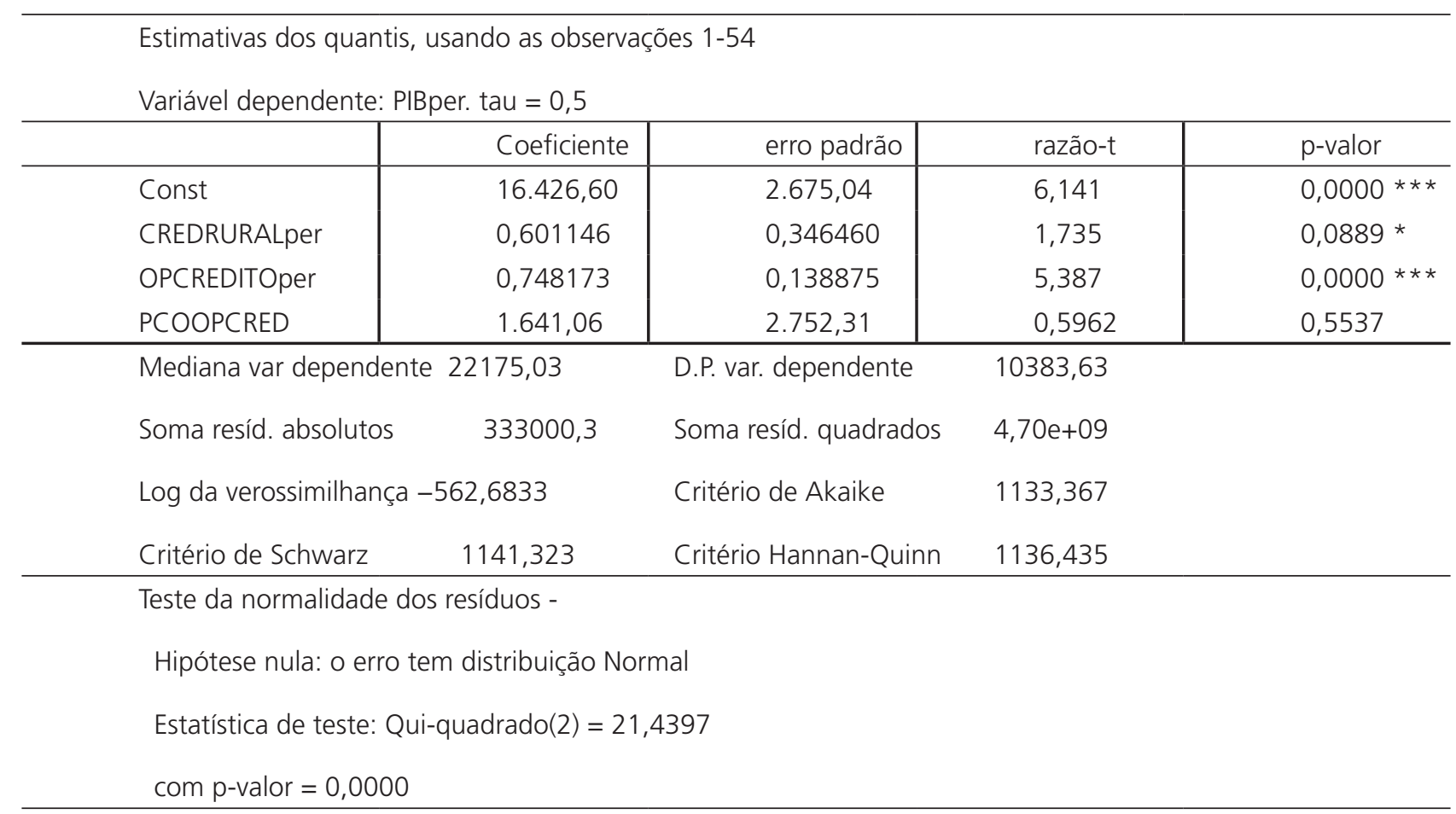




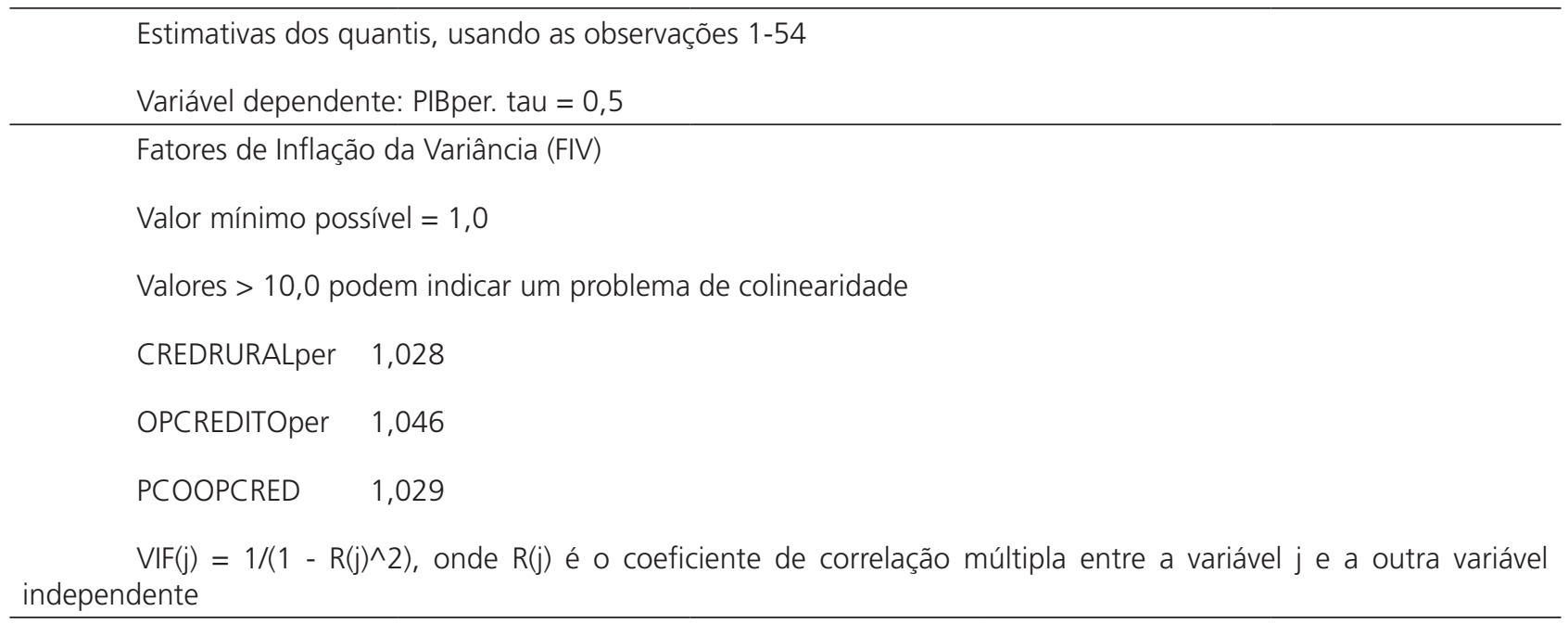

Fonte: Elaborado pelo autor.

De acordo com os resultados obtidos no modelo estimado, Tabela 3, para mesorregião Centro Oriental, para cada real concedido de crédito rural o PIB per capita apresentou um aumento de R\$ 0,61 e para cada real concedido por intermédio das operações de crédito o acréscimo foi de $R \$ 0,75$. A presença de PAs de cooperativas de crédito não foi estatisticamente significativa para o crescimento econômico da mesorregião.

A Figura 5 destaca as 98 cidades que correspondem à mesorregião Metropolitana de
Porto Alegre, a mais populosa com mais de 5 milhões de habitantes e um PIB de R\$184.114.708.555,00, sendo a região que possui o maior volume de operações financeiras.A capital gaúcha, Porto Alegre, e Canoas são as principais cidades, com um PIB per capita de $\mathrm{R} \$ 46.122,79$ e $\mathrm{R} \$ 47.588,56$ respectivamente. Ainda, para essa mesorregião, cabe destaque especial para Triunfo com o maior PIB per capita do Estado, $\mathrm{R} \$ 268.381,39$.

Figura 5 - Previsão do PIB per capita na mesorregião Metropolitana.
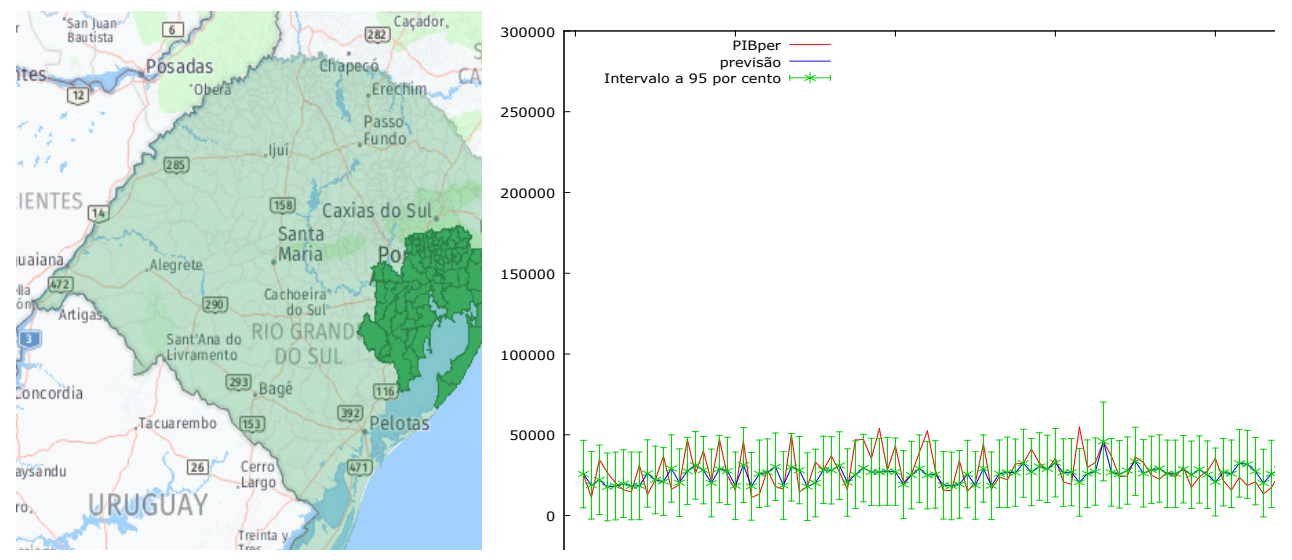

Fonte: Elaborado pelo autor.

Intervalo de 95\% de confiança.

PIB per capita para os municípios do Rio Grande do Sul.

Previsão do PIB per capita de acordo com o modelo proposto. 
A Tabela 4 apresenta o resultado da Regressão Alegre do Rio Grande do Sul. Quantílica da mesorregião Metropolitana de Porto

Tabela 4 - Modelo RQ Metropolitana

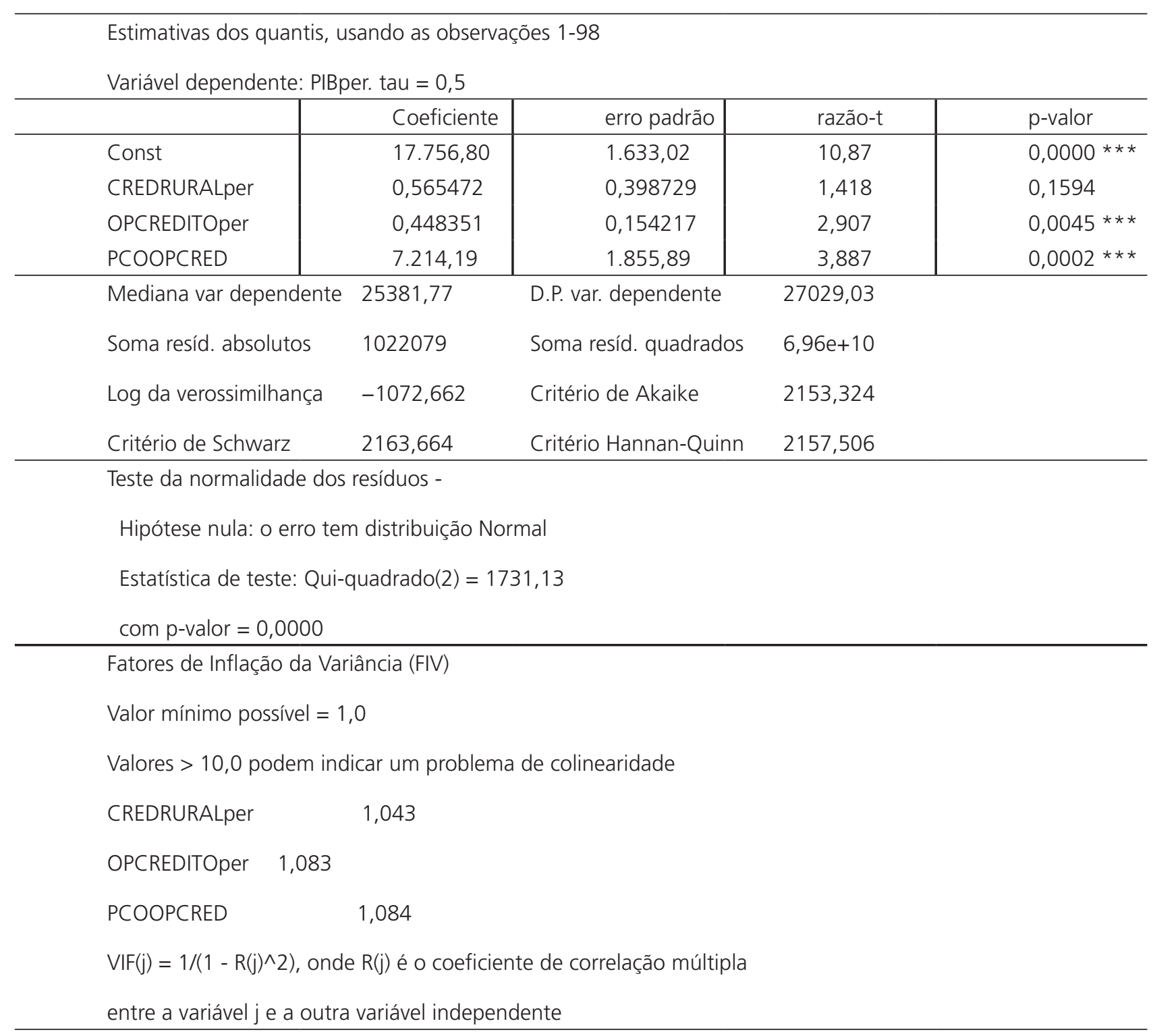

Fonte: Elaborado pelo autor.

Conforme o modelo proposto para o estudo, Tabela 4, o valor concedido por intermédio do crédito rural per capita não foi significativo para o PIB per capita da mesorregião metropolitana. Para cada real em operações de crédito per capita o PIB per capita apresentou um aumento de $\mathrm{R} \$ 0,45$ e a presença de cooperativas de crédito foi considerado aspecto favorável para o crescimento econômico, com um PIB per capita $R \$ 7.214,19$ superior às cidades que não possuem PAs de cooperativas de crédito. 
A mesorregião Nordeste do Rio Grande do Sul, Figura 6, engloba 54 municípios, com um PIB de $R \$$ 46.976.734.698,00 e uma população com um pouco mais de 1 milhão de habitantes. A principal cidade é Caxias do Sul, com um PIB de R\$ 20.637.191.756,00 e uma população de 480 mil habitantes.

Figura 6 - Previsão do PIB per capita na mesorregião Nordeste.


Fonte: Elaborado pelo autor.

- Intervalo de $95 \%$ de confiança.

PIB per capita para os municípios do Rio Grande do Sul.

- Previsão do PIB per capita de acordo com o modelo proposto.

A Tabela 5 apresenta o resultado da Regressão do Sul.

Quantílica da mesorregião Nordeste do Rio Grande

Tabela 5 - Modelo RQ Nordeste

Estimativas dos quantis, usando as observações 1-54

Variável dependente: PIBper. tau $=0,5$

\begin{tabular}{|c|c|c|c|c|}
\hline & Coeficiente & erro padrão & razão-t & p-valor \\
\hline Const & $20.327,80$ & 6090,43 & 3,338 & $0,0016 * * *$ \\
\hline CREDRURALper & 1,74549 & 0,368734 & 4,734 & $0,0000 * * *$ \\
\hline OPCREDITOper & 0,271249 & 0,390542 & 0,6945 & 0,4906 \\
\hline PCOOPCRED & 3261,09 & 6208,41 & 0,5253 & 0,6017 \\
\hline \multicolumn{2}{|c|}{ Mediana var dependente } & D.P. var. dependente & 28206,73 & \\
\hline \multicolumn{2}{|c|}{ Soma resíd. absolutos } & Soma resíd. quadrados & $3,28 e+10$ & \\
\hline Log da verossimilhança & $-603,4074$ & Critério de Akaike & 1214,815 & \\
\hline Critério de Schwarz & 1222,771 & Critério Hannan-Quinn & 1217,883 & \\
\hline
\end{tabular}




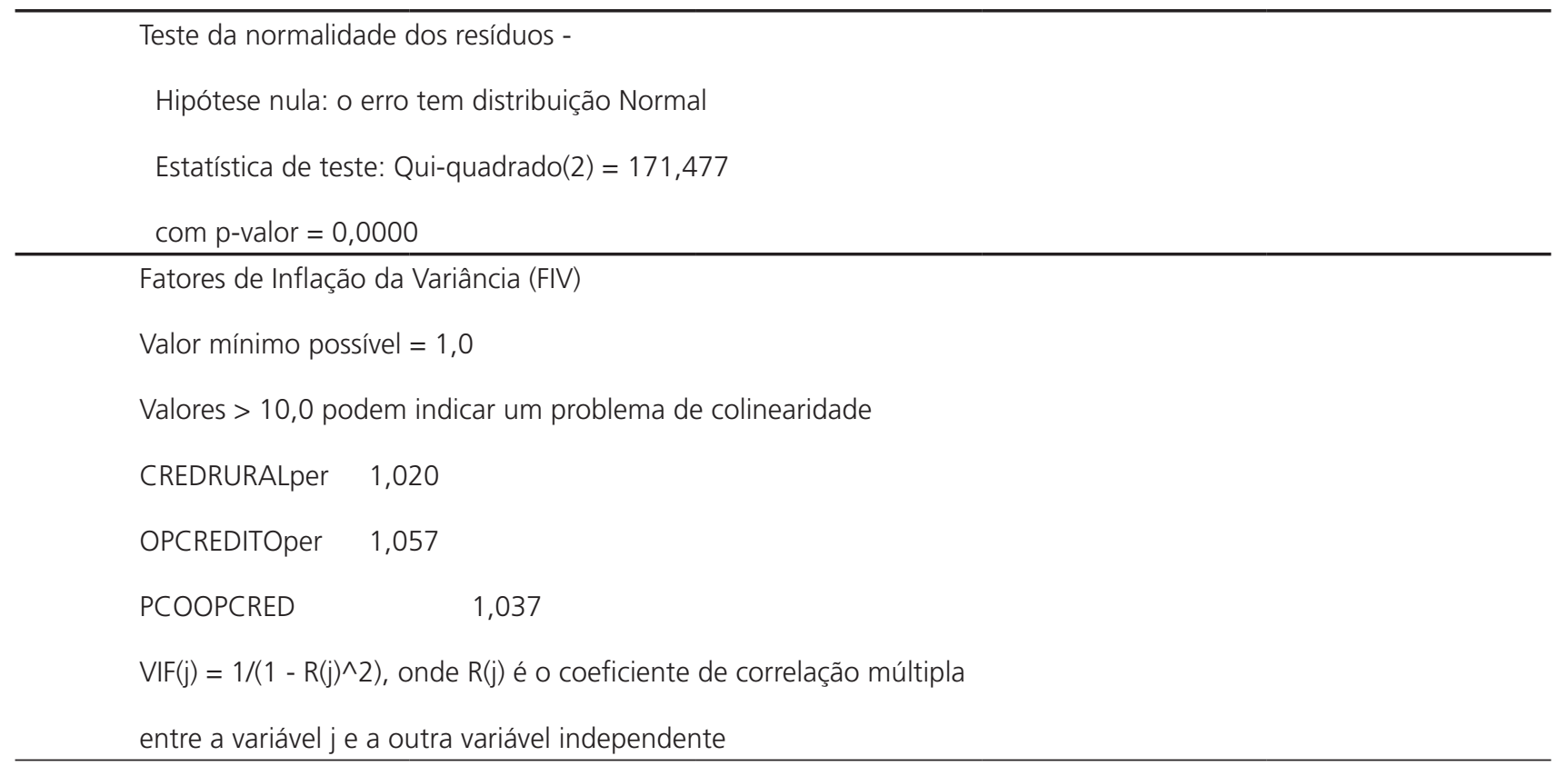

Fonte: Elaborado pelo autor.

Para mesorregião Nordeste do Rio Grande do Sul, conforme modelo estimado, Tabela 5, para cada real concedido de crédito rural gerou um aumento de $R \$ 1,75$ no PIB per capita. Já as operações de crédito não apresentaram resultado significativo para o modelo aplicado nessa mesorregião, assim como a presença de cooperativas de crédito.
Conforme a Figura 7, observam-se as 216 cidades localizadas na mesorregião Noroeste do Rio Grande do Sul, com uma população de 2 milhões de habitantes. As cidades de Cruz Alta, Erechim e Passo Fundo são as mais representativas, com um PIB de $R \$ 3.001 .468 .831,00, R \$ 4.262 .167 .173,00$ e $R \$ 7.817 .961 .526,00$, respectivamente.

Figura 7 - Previsão do PIB per capita na mesorregião Noroeste.
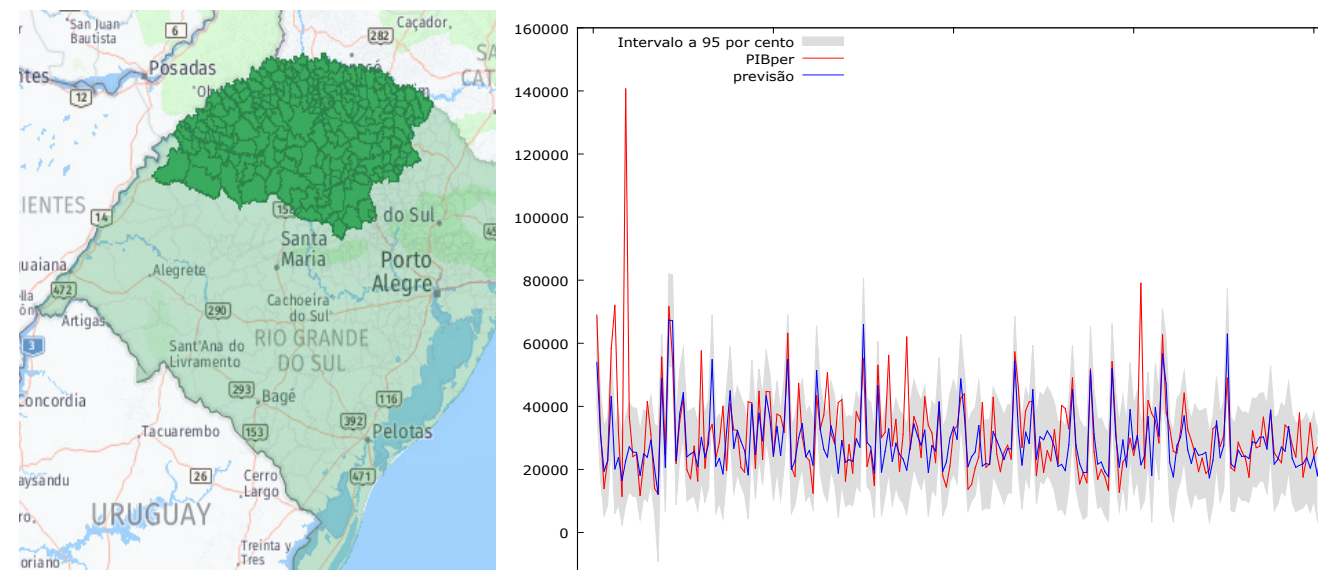

Fonte: Elaborado pelo autor.

Xxxx Intervalo de 95\% de confiança.

------- PIB per capita para os municípios do Rio Grande do Sul.

Previsão do PIB per capita de acordo com o modelo proposto. 
A Tabela 6 apresenta o resultado da Regressão do Sul. Quantílica da mesorregião Noroeste do Rio Grande

Tabela 6 - Modelo RQ Noroeste

Estimativas dos quantis, usando as observações 1-216

Variável dependente: PIBper. tau $=0,5$

\begin{tabular}{|c|c|c|c|c|c|c|}
\hline & \multicolumn{2}{|l|}{ Coeficiente } & erro padrão & razão-t & & p-valor \\
\hline Const & \multicolumn{2}{|l|}{$10.563,80$} & 2640,49 & 4,001 & & 0,0000 \\
\hline CREDRURALper & \multicolumn{2}{|l|}{2,05480} & 0,119834 & 17,15 & & 0,0000 \\
\hline OPCREDITOper & \multicolumn{2}{|c|}{$-0,00837548$} & 0,00757708 & $-1,105$ & & 0,2703 \\
\hline PCOOPCRED & \multicolumn{2}{|l|}{$5.266,17$} & 2567,35 & 2,051 & & $0,0415 * *$ \\
\hline \multicolumn{2}{|c|}{ Mediana var dependente 28001,46} & \multicolumn{2}{|c|}{ D.P. var. dependente } & & & \\
\hline Soma resíd. absolutos & 1528514 & \multicolumn{2}{|c|}{ Soma resíd. quadrados } & $3,52 \mathrm{e}+10$ & & \\
\hline Log da verossimilhança & $-2280,458$ & \multicolumn{2}{|c|}{ Critério de Akaike } & 4568,916 & & \\
\hline Critério de Schwarz & 4582,417 & \multicolumn{2}{|c|}{ Critério Hannan-Quinn } & & & \\
\hline
\end{tabular}

Teste da normalidade dos resíduos -

Hipótese nula: o erro tem distribuição Normal

Estatística de teste: Qui-quadrado(2) $=561,522$

com p-valor $=0,0000$

Fatores de Inflação da Variância (FIV)

Valor mínimo possível $=1,0$

Valores $>10,0$ podem indicar um problema de colinearidade

CREDRURALper $\quad 1,003$

OPCREDITOper $\quad 1,003$

PCOOPCRED $\quad 1,001$

$\operatorname{VIF}(j)=1 /(1-R(j) \wedge 2)$, onde $R(j)$ é o coeficiente de correlação múltipla entre a variável j e a outra variável independente

Fonte: Elaborado pelo autor.

Para a mesorregião Noroeste do Rio Grande do Sul, conforme resultado do modelo estimado na Tabela 6, para cada real concedido de crédito rural gerou um aumento de $\mathrm{R} \$ 2,05$ no PIB per capita. A variável operações de crédito não foi significativa para mesorregião em análise. A presença de PAs de cooperativas de crédito representou um aumento médio de $\mathrm{R} \$ 5.266,17$ no PIB per capita nos municípios em comparação às cidades que não possuem tais serviços.

Com 25 municípios, a mesorregião Sudeste do Rio Grande do Sul, Figura 8, possui uma população de 955.325 habitantes e obteve um PIB de $R \$$ 22.630.558.182,00, sendo Pelotas e 
Rio Grande as principais cidades com um PIB de respectivamente.

$R \$ 7.389 .940 .083,00$ e $R \$ 7.274 .579 .588,00$

Figura 8 - Previsão do PIB per capita na mesorregião Sudeste.
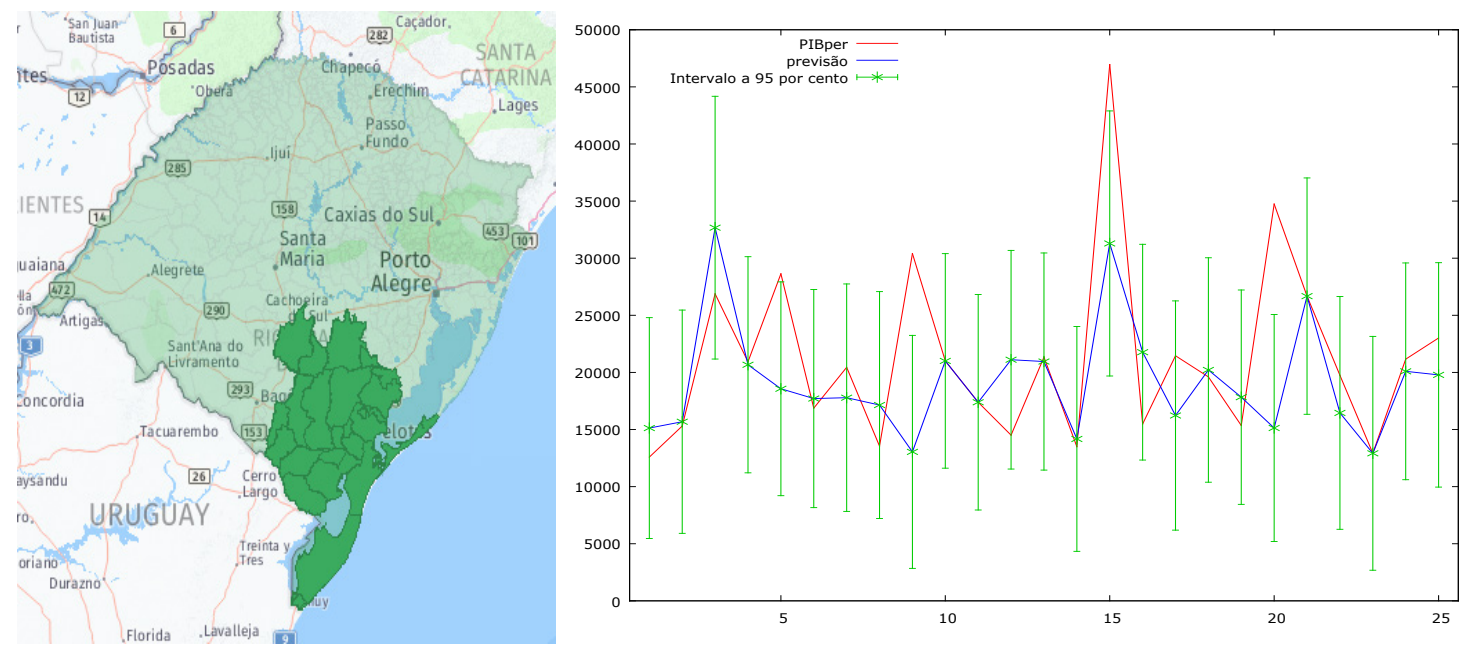

Fonte: Elaborado pelo Autor.

Intervalo de 95\%.

PIB per capita para os municípios do Rio Grande do Sul.

Previsão do PIB per capita de acordo com o modelo proposto.

A Tabela 7 apresenta o resultado da Regressão Quantílica da mesorregião Sudeste do Rio Grande do Sul.

Tabela 7 - Modelo RQ Sudeste

Estimativas dos quantis, usando as observações 1-25

Variável dependente: PIBper. tau $=0,5$

\begin{tabular}{l|c|c|c|c}
\hline & Coeficiente & erro padrão & razão-t & p-valor \\
\hline Const & $11.294,90$ & 2720,94 & 4,151 & $0,0005 * * *$ \\
CREDRURALper & 1,76732 & 0,377393 & 4,683 & $0,0001 * * *$ \\
OPCREDITOper & 0,250984 & 0,319407 & 0,7858 & 0,4408 \\
PCOOPCRED & $1.403,41$ & 2216,81 & 0,6331 & 0,5335 \\
\hline Mediana var dependente & 20446,11 & D.P. var. dependente & 7901,935 \\
Soma resíd. absolutos & 108636,4 & Soma resíd. quadrados & $1,23 e+09$ \\
Log da verossimilhança & $-251,7508$ & Critério de Akaike & 511,5017 \\
Critério de Schwarz & 516,3772 & Critério Hannan-Quinn & 512,8539 \\
\hline
\end{tabular}

Teste da normalidade dos resíduos -

Hipótese nula: o erro tem distribuição Normal

Estatística de teste: Qui-quadrado(2) = 12,7849

com p-valor $=0,00167412$ 


\begin{abstract}
Fatores de Inflação da Variância (FIV)
Valor mínimo possível = 1,0

Valores $>10,0$ podem indicar um problema de colinearidade

CREDRURALper $\quad 1,048$

OPCREDITOper $\quad 1,032$

PCOOPCRED $\quad 1,029$

$V I F(j)=1 /(1-R(j) \wedge 2)$, onde $R(j)$ é o coeficiente de correlação múltipla

entre a variável j e a outra variável independente
\end{abstract}

Fonte: Elaborado pelo autor.

De acordo com os resultados obtidos na regressão quantílica, do modelo estimado para a mesorregião Sudeste na Tabela 7, para cada real concedido de crédito rural o PIB per capita aumentou $\mathrm{R} \$ 1,77$. As variáveis operações de crédito per capita e a presença de PAs de cooperativas de crédito nos municípios não foram estatisticamente significativas para esse modelo.
A mesorregião Sudoeste do Rio Grande do Sul possui 19 municípios, Figura 9, com uma população de aproximadamente $740 \mathrm{mil}$ habitantes e um PIB de R\$17.494.312.986,00, com destaque para as cidades de Bagé com um PIB de $R \$ 2.563 .712 .547,00$ e Uruguaiana com $R \$$ 2.624.814.991,00.

Figura 9 - Previsão do PIB per capita na mesorregião Sudoeste.
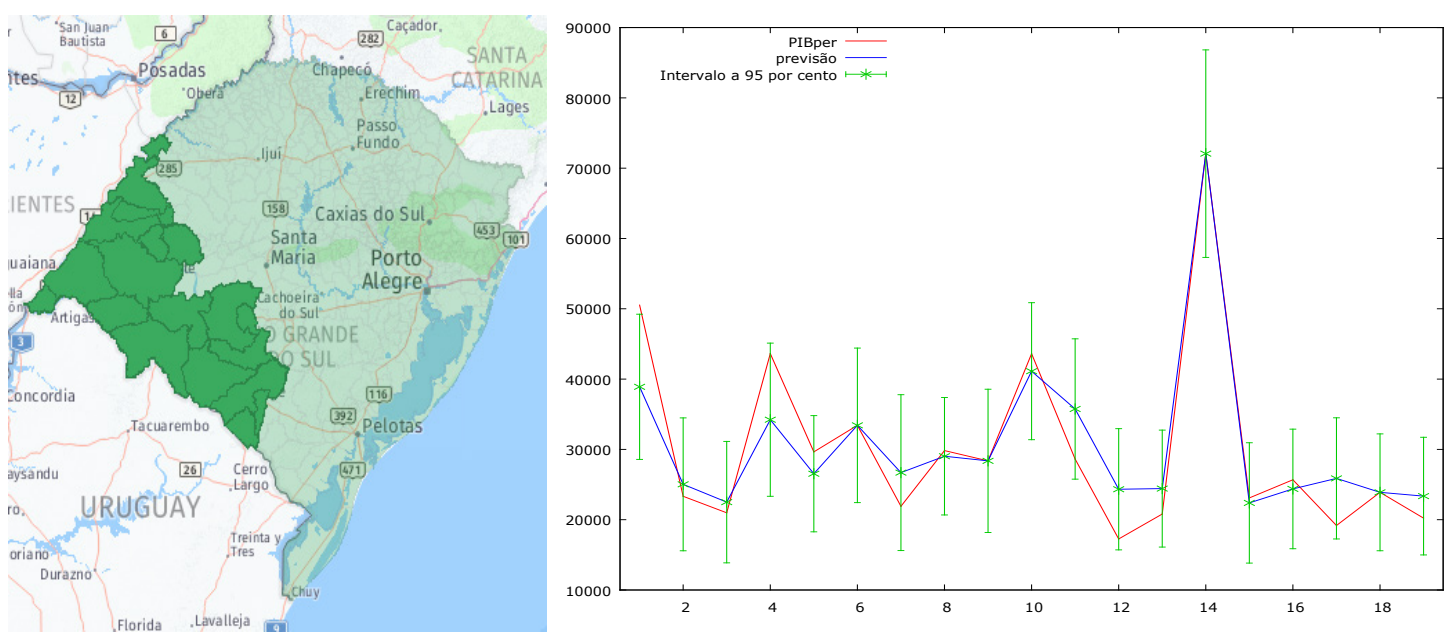

Fonte: Elaborado pelo autor.

Intervalo de 95\% de confiança.

- PIB per capita para os municípios do Rio Grande do Sul.

- Previsão do PIB per capita de acordo com o modelo proposto.

A Tabela 8 apresenta o resultado da Regressão Quantílica da mesorregião Sudoeste do Rio Grande do Sul. 
Tabela 8 - Modelo RQ Sudoeste

Estimativas dos quantis, usando as observações 1-19

Variável dependente: PIBper. tau $=0,5$

\begin{tabular}{|c|c|c|c|c|}
\hline & Coeficiente & erro padrão & razão-t & p-valor \\
\hline Const & $21.431,40$ & 4393,97 & 4,877 & $0,0002 * * *$ \\
\hline CREDRURALper & 1,15789 & 0,231007 & 5,012 & $0,0002 * * *$ \\
\hline OPCREDITOper & $-0,882098$ & 0,543839 & $-1,622$ & 0,1256 \\
\hline PCOOPCRED & $4.854,52$ & 5367,08 & 0,9045 & 0,3800 \\
\hline \multicolumn{2}{|c|}{ Mediana var dependente 2} & D.P. var. dependente & 13604,42 & \\
\hline Soma resíd. absolutos & 65108,52 & Soma resíd. quadrad & $4,39 e+08$ & \\
\hline Log da verossimilhança & $-186,8179$ & Critério de Akaike & 381,6357 & \\
\hline Critério de Schwarz & 385,4135 & Critério Hannan-Quir & 382,2751 & \\
\hline
\end{tabular}

Teste da normalidade dos resíduos -

Hipótese nula: o erro tem distribuição Normal

Estatística de teste: Qui-quadrado(2) = 3,12724

com p-valor $=0,209377$

Fatores de Inflação da Variância (FIV)

Valor mínimo possível $=1,0$

Valores $>10,0$ podem indicar um problema de colinearidade

CREDRURALper $\quad 1,503$

OPCREDITOper $\quad 2,215$

PCOOPCRED $\quad 1,704$

$\operatorname{VIF}(j)=1 /(1-R(j) \wedge 2)$, onde $R(j)$ é o coeficiente de correlação múltipla entre a variável j e a outra variável Fonte: Elaborado pelo autor.

Conforme os resultados obtidos na regressão quantílica para a mesorregião Sudoeste, Tabela 8, a partir das variáveis estabelecidas na metodologia, para cada real de crédito rural concedido o PIB per capita aumentou $\mathrm{R} \$ 1,16$. As operações de crédito e a existência de PAs de cooperativas de crédito no município (variável dummy) não foram estatisticamente significativas para o crescimento econômico.

A Tabela 9, Resumo dos modelos de Regressão Quantílica, apresenta os valores referentes aos coeficientes de cada variável independente, o erro padrão (entre parentes) e o número de observações de cada mesorregião pesquisada. 
Tabela 9 - Resumo dos modelos de Regressão Quantílica

\begin{tabular}{|c|c|c|c|c|}
\hline \multicolumn{5}{|c|}{ Variável dependente: PIB per capita } \\
\hline Variáveis Independentes & CREDRURAL & OPCREDITO & PCOOPCRED & OBSERVAÇÕES \\
\hline RS & $\begin{array}{c}1,46836 \\
(0,09535)\end{array}$ & - & $\begin{array}{c}3.303,96 \\
(1.405,81)\end{array}$ & 497 \\
\hline Centro Ocidental & $\begin{array}{c}1,50416 \\
(0,121081)\end{array}$ & $\begin{array}{c}0,214545 \\
(0,0764412)\end{array}$ & - & 31 \\
\hline Centro Oriental & $\begin{array}{c}0,601146 \\
(0,346460) \\
\end{array}$ & $\begin{array}{c}0,748173 \\
(0,138875) \\
\end{array}$ & - & 54 \\
\hline Metropolitana & - & $\begin{array}{c}0,448351 \\
(0,154217)\end{array}$ & $\begin{array}{c}7.214,19 \\
(1.855,89)\end{array}$ & 98 \\
\hline Nordeste & $\begin{array}{c}1,74549 \\
(0,368734)\end{array}$ & $\begin{array}{l}- \\
-\end{array}$ & - & 54 \\
\hline Noroeste & $\begin{array}{c}2,05480 \\
(0,119834)\end{array}$ & $\begin{array}{l}- \\
-\end{array}$ & $\begin{array}{c}5.266,17 \\
(2.567,35)\end{array}$ & 216 \\
\hline Sudeste & $\begin{array}{c}1,76732 \\
(0,377393)\end{array}$ & - & - & 25 \\
\hline Sudoeste & $\begin{array}{c}1,15789 \\
(0,231007)\end{array}$ & $\begin{array}{l}- \\
-\end{array}$ & - & 19 \\
\hline
\end{tabular}

Fonte: Elaborado pelo autor.

Com base nos resultados obtidos, a concessão de crédito rural contribuiu positivamente para o crescimento econômico do Rio Grande do Sul (analisando o efeito em todos os municípios), bem como a presença de PAs de cooperativas de crédito nos municípios gaúchos, enquanto as operações de crédito, de acordo com o modelo proposto, não foram significativas para gerar impacto no PIB per capita do Estado. Dentro desse mesmo contexto foram realizadas análises nas sete mesorregiões gaúchas.

Na mesorregião Centro Ocidental as variáveis crédito rural e operações de crédito proporcionaram aumento no PIB per capita da região, enquanto a variável presença de PAs de cooperativas de crédito não foi significativa.

Para a mesorregião Metropolitana as operações de crédito e a presença de posto de atendimento de cooperativas de crédito contribuíram para o crescimento econômico. Os valores correspondentes à concessão de crédito rural não foram significativos para o crescimento econômico dessa mesorregião. Já, para a mesorregião Nordeste, destacaramse como fatores positivos para o crescimento econômico, os valores concedidos por meio do crédito rural.

Os valores concedidos nas operações de crédito rural e a presença de PAs de cooperativas de crédito impactaram positivamente para o crescimento econômico da mesorregião Noroeste do Estado. Para a região Sudeste, a variável crédito rural contribuiu positivamente para o crescimento econômico regional. Por fim, para a mesorregião Sudoeste, o volume de recurso concedido por meio do crédito rural impactou positivamente para o PIB regional; e o valor negociado nas operações de crédito e a presença de cooperativas de crédito no município não apresentaram impacto significativo para o crescimento econômico da região. 
A pesquisa empírica confirmou a hipótese de que o sistema financeiro contribuiu para o crescimento econômico do Rio Grande do Sul como um todo, bem como para cada mesorregião estudada isoladamente. Com especial destaque para as regiões nordeste e noroeste, quanto à concessão de crédito rural, para as regiões centro oriental e metropolitana para as operações de crédito e para região metropolitana e noroeste pela presença de postos de atendimento das cooperativas de crédito.

\section{CONCLUSÕES}

A intermediação financeira promovida por agentes econômicos disponibiliza recursos financeiros para o mercado, o que tem sinalizado para uma relação positiva entre Sistema Financeiro e crescimento econômico. Nesse sentido, o propósito desta pesquisa foi analisar os impactos da oferta e do acesso ao crédito no crescimento econômico do Rio Grande de Sul, bem como para cada mesorregião isoladamente. A discussão partiu da oferta de crédito e da presença de instituições financeiras (cooperativas de crédito) como fornecedores de recursos financeiros alocados no setor produtivo. A literatura abordada neste trabalho afirma que quanto mais desenvolvido o sistema financeiro, maior será o valor destinando para o setor produtivo, o que promoverá um maior crescimento econômico.

As evidências empíricas desta pesquisa confirmaram os pressupostos teóricos quanto à relação positiva entre o sistema financeiro e o crescimento econômico. Na aplicação da técnica da regressão quantílica foi apresentado um mapeamento mais completo dos impactos das variáveis independentes (crédito rural, operações de crédito e presença de cooperativas de crédito) no crescimento econômico (PIB).

Na aplicação da regressão quantílica, observa-se, a partir dos resultados, uma relação positiva entre o sistema financeiro e crescimento econômico. Para o Rio Grande do Sul e a mesorregião Noroeste, a concessão de crédito rural e presença de cooperativas de crédito corroboraram para o crescimento econômico; para a mesorregião Centro Ocidental e Centro Oriental a concessão de crédito rural e as operações de crédito contribuíram para o PIB per capita da região; na mesorregião Metropolitana as operações de crédito e a presença de cooperativa de crédito nos municípios apresentaram uma relação positiva entre sistema financeiro e crescimento econômico; e nas mesorregiões Nordeste, Sudeste e Sudoeste a concessão de crédito rural foi significativa para o crescimento econômico. Cabe, dentro desse contexto, destacar a presença das cooperativas de crédito nos municípios na mesorregião Metropolitana e a concessão de crédito rural na mesorregião Noroeste como relevantes para o impacto positivo ao crescimento econômico, conforme os resultados obtidos.

Diante das avaliações realizadas, percebe-se que a oferta e o acesso ao crédito podem promover o crescimento econômico de maneira diferente para cada região, o que corrobora para uma percepção de que o efeito da concessão de crédito para economia está associado às potencialidades locais, como no caso das localidades voltadas para a atividade agropecuária.

Considerando a concessão de crédito direcionada para o setor agropecuário, as operações 
de crédito ofertadas aos demais setores e a atuação de cooperativas de crédito como agentes nas intermediações financeiras na economia do Rio Grande do Sul, os resultados encontrados confirmam que as variáveis independentes selecionadas foram significativas para demonstrar os impactos do sistema financeiro no crescimento econômico do Estado. Sendo assim, o modelo RQ estimado, confirmou a hipótese sobre a existência de uma correlação positiva entre sistema financeiro e crescimento econômico para o Rio Grande do Sul e suas mesorregiões.

Esta pesquisa limitou-se a apresentar como agente financeiro somente as cooperativas de crédito, considerando a sua abrangência territorial no Rio Grande do Sul.
Os resultados obtidos podem ser considerados em novas pesquisas voltadas para a atuação do sistema financeiro e o crescimento econômico, com a inclusão de novas variáveis em propostas futuras, bem como servir de ferramenta de análise para os agentes financeiros como uma percepção das participações regionais e de mercado.

O presente trabalho foi realizado com apoio da Coordenação de Aperfeiçoamento de Pessoal Nível Superior - Brasil (CAPES) - Código de Financiamento 001.

This study was financed in part by the Coordenação de Aperfeiçoamento de Pessoal de Nível Superior - Brasil (CAPES) - Finance Code 001.

\section{REFERÊNCIAS}

Banco Central do Brasil - BCB. Disponível em: https://www3.bcb.gov.br/ifdata/. Acesso em; 08 de dez. 2017.

BEBCZUK, R. Asymmetric information in financial markets: introduction and applications.Cambridge University Press, 2003.

BUAINAIN, A. M.; ALVES, E.; SILVEIRA, J. M. da; NAVARRO, Z. (editores técnicos). O mundo rural no Brasil do século 21: a formação de um novo padrão agrário e agrícola. Brasília, DF: Embrapa, 2014.

CASTRO, C. B. Moeda e espaço: os casos das áreas metropolitanas de São Paulo, Rio de Janeiro, Belo Horizonte, Curitiba, Salvador e suas áreas de polarização. 2002. Dissertação (Mestrado), CEDEPLAR, UFMG. Belo Horizonte, 2005.
CHAVES, S. S. O cooperativismo de crédito no Brasil: evolução e perspectivas. In: DESAFIOS do Sistema Financeiro Nacional: o que falta para colher os benefícios da estabilidade conquistada. Rio De Janeiro: Elsevier-Campus, 2011. p. 69-97.

FIALHO, T. M. M.; JAYME JR, F. G.; HERMETO A. M. Desenvolvimento do sistema financeiro e pobreza no Brasil: uma análise multivariada. Economia e Sociedade, Campinas, v. 25, n. 1 (56), p. 247-278, abr. 2016.

Fundação de Economia e Estatística - FEE. Disponível em: https://dados.fee.tche.br/. Acesso em: 10 dez. 2018.

GOLDSMITH, R. Financial structure and development. New Haven and London: Yale University Press, 1969. 


\section{REFERÊNCIAS}

GUISO, L.; SAPIENZA, P.; ZINGALES, L. Does local financial development matter?CEPR Discussion Papers3307, 2002.

\section{GUJARATI, D. N.; PORTER, D. C. Econometria}

básica. 5. ed. Porto Alegre: AMGH, 2011.

Instituto Brasileiro de Geografia e Estatística - IBGE. Disponível em: https://www.ibge.gov. br/estatisticas-novoportal/economicas/contasnacionais.html. Acesso em: 05 dez. 2017.

IVO, G. A; CRUZ, D. B. F;CHINELATO, F. B; ZIVIANI, F. A expansão do crédito no Brasil: uma ferramenta para o desenvolvimento socioeconômico. Gestão \& Regionalidade, v. 32, n. 95, maio/ago. 2016.

KALDOR, N. The case for regional policies. Scottish Journal of Political Economy, v. 17, n. 3, p. 337-348, 1970.

KEYNES, J. M. The general theory of employment, interest and money. Nova York: Hartcourt Brace and World, 1964.

KEYNES, J. M. Treatise on Money, Collected Writtings $\mathrm{V}$ and $\mathrm{VI}$. London: MacMillan, 1930/1971.

KHAN, A. Financial development and economic growth. Federal Reserve Bank of Philadelphia, Working Papern. 99-11, set. 1999.

LEVINE, R. Financial development and economic growth: views and agenda. Journal of Economic Literature, n. 35, 1997.
MARIONI, L. da S.; VALE, V. de A.; PEROBELLI, F. S.; FREGUGLIA, R. da S. Uma Aplicação de Regressão Quantílica para Dados em Painel do PIB e do Pronaf. RESR, Piracicaba, v. 54, n. 02, p. 221-242, abr./jun. 2016.

MEINEN, E. Cooperativismo financeiro: virtudes e oportunidades. Ensaios sobre a perenidade do empreendimento cooperativo. Brasília: Confebras, 2016.

MYRDAL, G. Teoria econômica e regiões subdesenvolvidas. Rio de Janeiro: Saga, 1968.

PAIVA, B. G. M. de; SANTOS, N. M. B. F. dos. Um estudo do cooperativismo de crédito no Brasil. Revista da Universidade Vale do Rio Verde, Três Corações, v. 15, n. 2, p. 596-619, ago./dez. 2017.

PERROUX, F. A economia do século XX. Lisboa: Herder, 1967.

PINHEIRO, M. A. H. Cooperativas de Créditos: história e evolução normativa no Brasil. 6. ed. Brasilia: BCB, 2008.

PINHO, D. B.; PALHARES, V. M. A. O cooperativismo de crédito no Brasil: do século XX ao século XXI. Santo André: Editora Confebras, 2004.

PINTOR, G. M. Z. de.; PINTOR, E. de.; OLIVEIRA, G. B. de.; WESZ JUNIOR V.J. Crédito Rural e crescimento econômico na Mesorregião Oeste do Paraná. Revista do Desenvolvimento Regional Faccat, Taquara, v. 13, n. 2, jul./dez. 2016. 


\section{REFERÊNCIAS}

REICHSTUL, D; LIMA, G. T. Causalidade entre crédito bancário e nível de atividade econômica na região Metropolitana de São Paulo: algumas evidências empíricas. Estud. econ., São Paulo, v. 36, n. 4, p. 779-801, out./dez. 2006.

\section{SCHUMPETER, J. The theory of economic}

development. Cambridge. Mass.: Harvard University Press, 1911.

\section{SHAW, E. W. Financial deepening in} economic development. New York: Oxford University Press, 1973.

SICSÚ, J.; CROCCO, M. Em busca de uma teoria da localização das agências bancárias: algumas evidências do caso brasileiro. Economia, v. 4, n. 1, jan./jun. 2003.

SILVA, E. N da; PORTO JÚNIOR, S. da S. Sistema financeiro e crescimentoeconômico: uma aplicação de regressãoquantílica.Econ. Aplic., v. 10, n, 3, p. 425-442, jul./set. 2006.

\section{VARIAN, H. Microeconomia - Princípios} Básicos - Uma Abordagem Moderna. Ed. Campus. 1990.

WOOLDRIDGE， J. M. Introdução à econometria: uma abordagem moderna. São Paulo: Cengage Learning, 2013.

\section{Ricardo Höher ${ }^{1}$}

Doutor em Economia do Desenvolvimento pela Pontifícia Universidade Católica do Rio Grande do Sul - PUCRS (2018). Mestre em Economia pela Universidade do Vale do Rio dos Sinos - Unisinos (2009). Graduado em Ciências Contábeis pela Universidade Federal de Santa Maria - UFSM (2003). Atualmente é professor adjunto III (DE) da UFSM, atuando principalmente nas áreas de agronegócio, cooperativismo e desenvolvimento regional. Universidade Federal de Santa Maria - UFSM - Brasil. E-mail: ricardo.hoher@ufsm.br

\section{Osmar Tomaz de Souza²}

Graduado em Ciências Econômicas pela Universidade Estadual de Maringá (1992), mestrado em Economia Rural pela Universidade Federal do Rio Grande do Sul (1999), doutorado em Desenvolvimento e Meio Ambiente pela Universidade Federal do Paraná (2006), doutorado-sanduíche pela Université Paris X Nanterre (França) (20042005) e pós-doutorado em Economia Agrária e dos Recursos Naturais pela Université Paris Ouest Nanterre - La Defense (França) (2013-2014). Já atuou como consultor em projetos do Instituto Interamericano de Cooperação para a Agricultura - IICA (2000-2002) e da FAO (2002). Atualmente, é professor em tempo integral da PUCRS e do Programa de Pós-Graduação em Economia (PPGE-PUCRS). Tem experiência na área de Economia, com ênfase em Economia Regional e Economia Rural, Desenvolvimento e Meio Ambiente, com pesquisas e projetos relacionados aos seguintes temas: desenvolvimento regional, desenvolvimento rural, Agricultura e meio ambiente. Pontifícia Universidade Católica do Rio Grande do Sul - PUCRS - Brasil. E-mail:

Data da Submissão :19/11/2018

Data de Aceite: 30/04/2019

\section{Footnotes}

1 Quantis desejados

2 Grau de confiança - *** significante ao nível de 1\%; ** significante ao nível de 5\%; e * significante ao nível de 10\%. 